\title{
Dynamic state power system fault monitoring and protection with phasor measurements and fuzzy based expert system
}

\author{
Ravi Ponnala ${ }^{1}$, Muktevi Chakravarthy ${ }^{2}$, Suraparaju Venkata Naga Lakshmi Lalitha ${ }^{1}$ \\ ${ }^{1}$ Department of Electrical and Electronics Engineering, Koneru Lakshmaiah Education Foundation, Guntur, India \\ ${ }^{2}$ Department of Electrical and Electronics Engineering, Vasavi College of Engineering, Hyderabad, India
}

\begin{tabular}{l} 
Article Info \\
\hline Article history: \\
Received Jun 24, 2021 \\
Revised Nov 12, 2021 \\
Accepted Jan 13, 2022 \\
\hline
\end{tabular}

Keywords:

Dynamic state monitoring

Fuzzy

Micro grid

Phasor measurements

Protection

\begin{abstract}
The main aim of this paper is building of a small micro grid test bed system with a few sources, and few loads with various types of lumped resistive (R), capacitive (C) and inductive (L) elements. Before the advent of electric smart grid every load is facilitated with its own electromagnetic. Slowly with an advancement of protection system numerical relays came into existence. Because in the numerical relays the communication between the relays and communication with central computer is possible, with this a coordinative protection system was evolved. For the monitoring and protection of system in dynamic state many of the numerical relays were now replaced by intelligent electronic devices. The system is to be centrally controlled with an improvement in data communications and the artificial intelligence into power system made it is possible to control the power system centrally. In this paper, it is presented that the fault is monitoring and protection against different types of faults, such as frequency variations, voltage variations and different fault conditions using fuzzy based expert system (FBES). The proposed protection scheme is adaptive for frequency variations, voltage variations and fault levels. The FBES scheme is implemented in the LabVIEW software with MAMDANI structure.
\end{abstract}

This is an open access article under the CC BY-SA license.

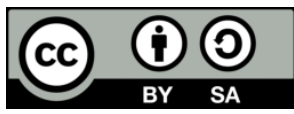

\section{Corresponding Author:}

Ravi Ponnala

Department of Electrical and Electronics Engineering

Koneru Lakshmaiah Education Foundation, Guntur, India

Email: ravi.ponnala@staff.vce.ac.in

\section{INTRODUCTION}

Nowadays in the modern world, the utilization of electrical energy is increasing very rapidly. To satisfy the growing demand of electrical energy, requires new resources and allocate them properly according to dynamic changes of load demand. For proper utilization of electrical energy, there should be proper monitoring and fast control system. This is where the concept of dynamic state monitoring of the power system comes into the picture [1]. For the dynamic state monitoring of power system, the collection of data from the system should be at a faster level. According to the IEEE standard for dynamic state monitoring of the system at least 10 samples should be read in a second [2]. In the existed power system for the monitoring, supervisory control and data acquisition (SCADA) and energy management system (EMS) are read the sample at every 3 to 4 seconds. Therefore these are given limited awareness about the power system steady state operation. For the better protection performance of power system, it is required a good monitoring system in a dynamic state. Nowadays with the development of intelligent electronic devices the data collection rate is improved and it is fed to the computer, this helps to monitor the system in the dynamic state. With collected data phasor values of current and voltage signals is directly calculated at point of data collection. With the calculated phasor values power calculation and fault monitoring is possible. The 
conventional power system fault monitoring methods is give limited information [3] about the system. For the dynamic state power system fault monitoring and protection intelligence based system is required [4]. For this intelligence based fault monitoring and protection purpose FBES system is proposed. This FBES system will give complete solution for the power system monitoring and protection in the dynamic state. For this dynamic state monitoring and protection purpose a test bed system is created with a controlled voltage source, transmission line, couple of loads, data collection and protection system [5]. With the controlled voltage source, voltage and frequency variations are created. With transmission line model different types of shunt (symmetrical/unsymmetrical) faults are created. With the loads normal load and over load conditions are created. On the developed test bed system the following case studies are carried out and validated in dynamic state conditions according to the IEEE C37.118 standard they are; i) real time current and voltage phasor calculation, ii) monitoring of fault with FBES, iii) FBES based protection system. All these are implemented in the LabVIEW software with real signals and simulated signal.

\section{CURRENT AND VOLTAGE PHASOR CALCULATION}

For the calculation of current and voltage phasor values, a 24-point DFT technique is used [1]. For the different types of case studies, micro grid single line diagram is shown in Figure 1. In this controlled voltage source, different loads are used for different case studies. For different case studies the data is collected at the source side and fed to the computer through data acquisition card for phasor calculation under different case studies.

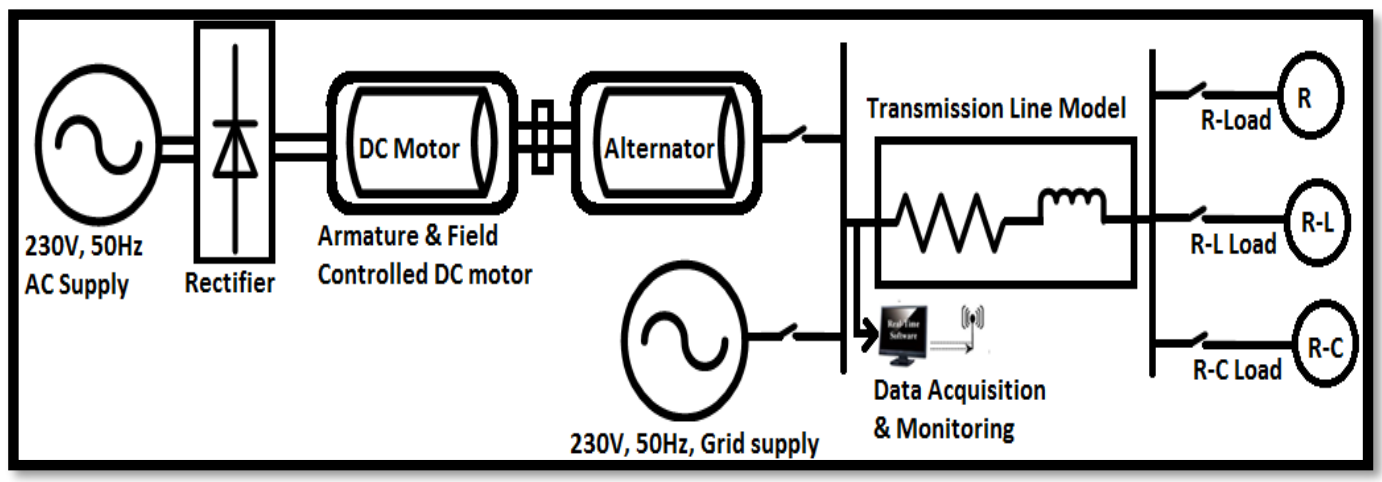

Figure 1. Micro grid model block diagram representation

In general, areal time $\mathrm{AC}$ wave form is represented as:

$$
\mathrm{y}(\mathrm{t})=\mathrm{Ymcos}(\omega t+\phi)
$$

Here $(\omega t+\phi)$ represents the instantaneous phase angle, and $\phi$ represents the initial phase angle of the signal. The $\phi$ will gives the position of the waveform at $\mathrm{t}=0$. The phasor representation AC signal (1) is given by:

$$
\mathrm{Y}=\frac{\mathrm{Ym}}{\sqrt{2}} e^{j \phi}=\frac{\mathrm{Ym}}{\sqrt{2}}(\cos \phi+\mathrm{j} \sin \phi)
$$

Where $Y_{m}$ : the peak value of the signal. The given signal discrete fourier series is given by:

$$
\mathrm{Y}_{k}=\frac{\sqrt{2}}{N} \sum_{n=0}^{N-1} \mathrm{Y}_{n}[\cos (\mathrm{kn} \theta)-j \sin (\mathrm{kn} \theta)]
$$

The flow chart for the calculation phasor using DFT is shown in the Figure 2. The simulation diagram for the phasor calculation based on the flow chart is shown in the Figure 3. 


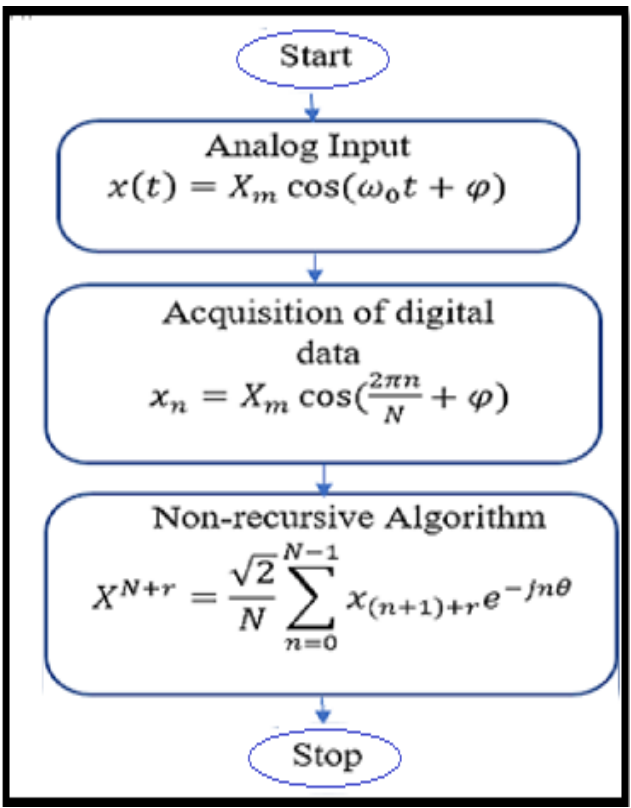

Figure 2. Non-recursive DFT algorithm flow chart

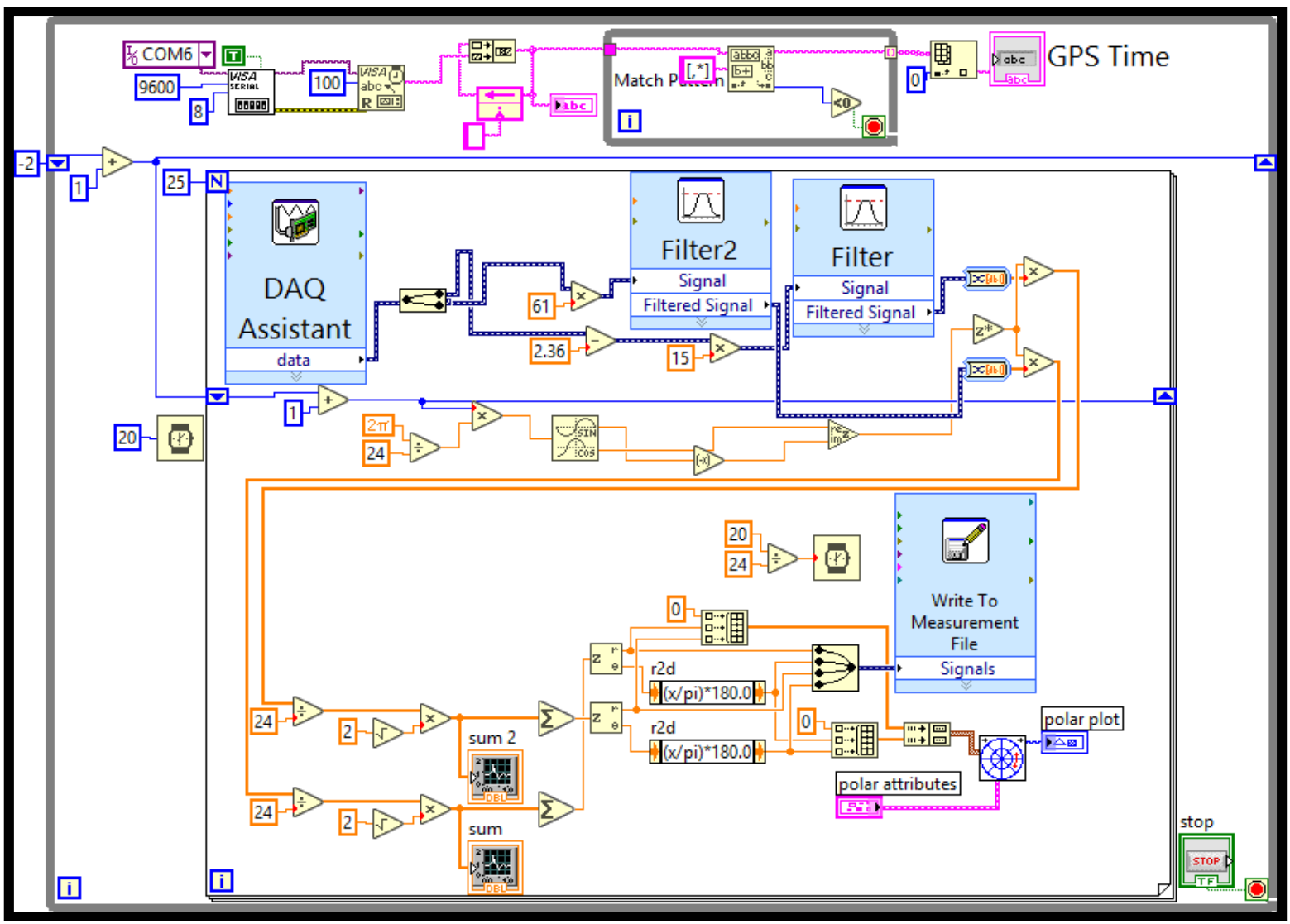

Figure 3. Simulation diagram for current and voltage phasor calculations non-recursive DFT with 24-point technique with GPS timing in LabVIEW

The real time signal is fed to the simulation circuit with a DAQ assistant block. The real time current and voltage signals phasor values are calculated by using the 24-point DFT technique [6]-[9]. These phasor values are used for the protection purpose [10] because in this phasor values along with magnitude, 
phase angle also available. With the magnitude and phase angle values fault monitoring and protection is possible [11]-[15].

\section{MONITORING FAULT CONDITIONS WITH FBES}

For the reliable operations of power system a good fault monitoring system is required [16]. Now a days due to the decentralized power generation the power system operations are very complex, for this intelligence is required [17]. For the different case studies on the transmission line a $200 \mathrm{kM}, 220 \mathrm{kV}$ and $50 \mathrm{~Hz}$ is transmission line is considered [18], [19]. The transmission line details are given in the Table 1. For the dynamic state monitoring of the power system different types of faults are created on the artificial transmission line model with a controlled voltage source [20], [21]. A different type of faults includes variation of voltage, variation of frequency, and different types of shunt faults on the transmission line [22]. With a total 27 types of abnormal/fault conditions are created and checked by the FBES. The fault identification flow chart with FBES rules is shown in the Figure 4.

Table 1. Details of $200 \mathrm{kM}$ transmission line model

\begin{tabular}{cc}
\hline Parameter & Nominal values \\
\hline 3-phase source rated voltage & $220 \mathrm{KV}$ \\
Short-circuit rating & $1250 \mathrm{MVA}$ \\
Base power & $200 \mathrm{MVA}$ \\
Frequency & $50 \mathrm{~Hz}$ \\
source $X / R$ ratio & 10 \\
Earth resistivity & $90 \Omega \mathrm{m}$ \\
\hline
\end{tabular}

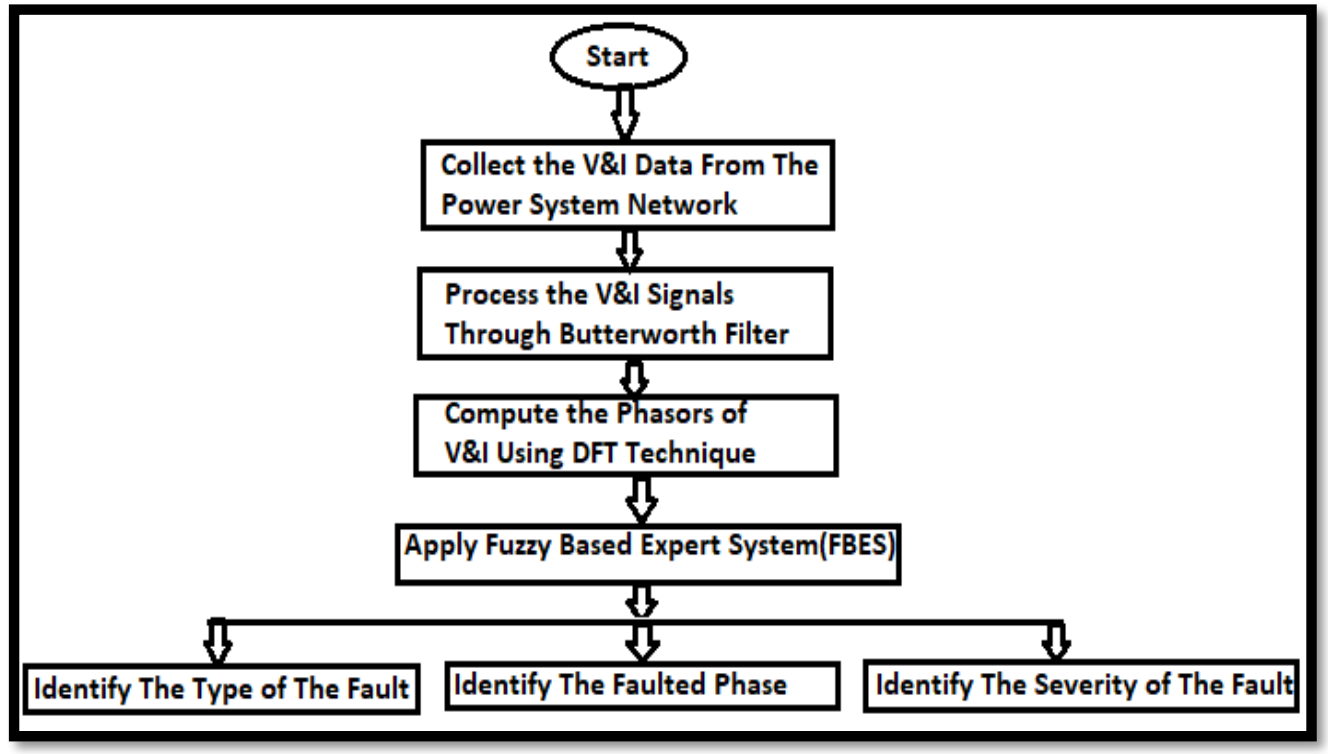

Figure 4. The outline of FBES fault monitoring system

The real signal of voltage, current waveforms and its polar form is shown in Figure 5. This results are accurate than results [19]-[22] for dynamic state power system monitoring. The FBES rules for various types of fault conditions monitoring are given as:

1. If 'Iy' is 'Small' \& 'Ib' is 'Small' \& 'Ir' is 'Small' then 'the system condition' is 'No Problem'

2. If 'Iy' is 'Small' \& 'Ib' is 'Small' \& 'Ir' is 'Normal' then 'the system condition' is 'Caution'

3. If 'Iy' is 'Small' \& 'Ib' is 'Small' \& 'Ir' is 'More' then 'the system condition' is 'Severe Fault'

4. If 'Iy' is 'Small' \& 'Ib' is 'Normal' \& 'Ir' is 'Small' then 'the system condition' is 'Caution'

5. If 'Iy' is 'Small' \& 'Ib' is 'Normal' \& 'Ir' is 'Normal' then 'the system condition' is 'Caution'

6. If 'Iy' is 'Small' \& 'Ib' is 'Normal' \& 'Ir' is 'More' then 'the system condition' is 'Severe Fault'

7. If 'Iy' is 'Small' \& 'Ib' is 'More' \& 'Ir' is 'Small' then 'the system condition' is 'Severe Fault'

8. If 'Iy' is 'Small' \& 'Ib' is 'More' \& 'Ir' is 'Normal' then 'the system condition' is 'Severe Fault' 
9. If 'Iy' is 'Small' \& 'Ib' is 'More' \& 'Ir' is 'More' then 'the system condition' is 'Very Severe Fault' 10. If 'Iy' is 'Normal' \& 'Ib' is 'Small' \& 'Ir' is 'Small' then 'the system condition' is 'Caution' 11. If 'Iy' is 'Normal' \& 'Ib' is 'Small' \& 'Ir' is 'Normal' then 'the system condition' is 'Caution' 12. If 'Iy' is 'Normal' \& 'Ib' is 'Small' \& 'Ir' is 'More' then 'the system condition' is 'Severe Fault' 13. If 'Iy' is 'Normal' \& 'Ib' is 'Normal' \& 'Ir' is 'Small' then 'the system condition' is 'Caution' 14. If 'Iy' is 'Normal' \& 'Ib' is 'Normal' \& 'Ir' is 'Normal' then 'the system condition' is 'Caution' 15. If 'Iy' is 'Normal' \& 'Ib' is 'Normal' \& 'Ir' is 'More' then 'the system condition' is 'Severe Fault' 16. If 'Iy' is 'Normal' \& 'Ib' is 'More' \& 'Ir' is 'Small' then 'the system condition' is 'Severe Fault' 17. If 'Iy' is 'Normal' \& 'Ib' is 'More' \& 'Ir' is 'Normal' then 'the system condition' is 'Very Severe Fault' 18. If 'Iy' is 'Normal' \& 'Ib' is 'More' \&'Ir' is 'More' then 'the system condition' is 'Very Very Severe Fault' 19. If 'Iy' is 'More' \& 'Ib' is 'Small' \& 'Ir' is 'Small' then 'the system condition' is 'Severe Fault' 20. If 'Iy' is 'More' \& 'Ib' is 'Small' \& 'Ir' is 'Normal' then 'the system condition' is 'Severe Fault' 21. If 'Iy' is 'More' \& 'Ib' is 'Small' \& 'Ir' is 'More' then 'the system condition' is 'Very Severe Fault' 22. If 'Iy' is 'More' \& 'Ib' is 'Normal' \& 'Ir' IS 'Small' then 'the system condition' is 'Severe Fault' 23. If 'Iy' is 'More' \& ' $\mathrm{Ib}$ ' is 'Normal' \& 'Ir' is 'Normal' then 'the system condition' is 'Very Severe Fault' 24. If 'Iy' is 'More' \& 'Ib' is 'Normal' \& 'Ir' is 'More' then 'the system condition' is 'Very Very Severe Fault' 25. If 'Iy' is 'More' \& 'Ib' is 'More' \& 'Ir' is 'Small' then 'the system condition' is 'Very Severe Fault' 26. If 'Iy' is 'More' \& 'Ib' is 'More' \& 'Ir' is 'Normal' then 'the system condition' is 'Very Very Severe Fault' 27. If 'Iy' is 'More' \& 'Ib' is 'More' \& 'Ir' is 'More' then 'the system condition' is 'Very Very Severe Fault'

With the fuzzy based monitoring the calculated phasor values and the wave forms under faulted condition are shown in the Figure 5.

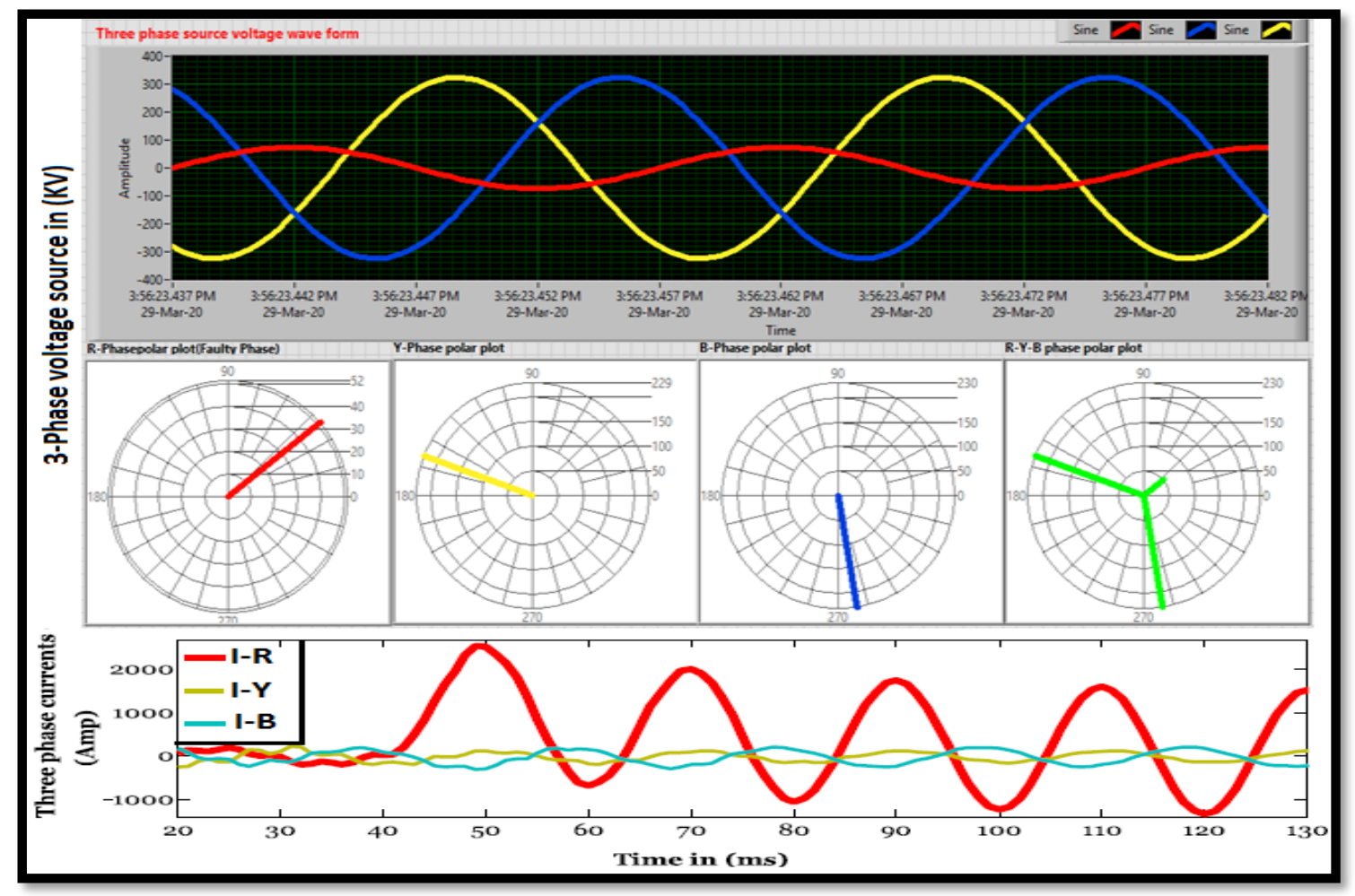

Figure 5. Power system dynamic state fault monitoring system with FBES

\section{FBES BASED PROTECTION SYSTEM}

Protection of precious equipment from the abnormal condition is very important in the power system. The software based protection circuit is shown in the Figure 6. In the simulation circuit protection is implemented for the variation of voltage magnitude from the rated and accepted values. Also this protection is extended for the overload and frequency variation from the rated and the accepted values. When the abnormal condition is occurred in the power system then trip signal is generated from the simulation circuit 
[23]-[25]. But for the clearance of the different faults required time is different. This time for various faults is decided with the FBES with a basis of inverse definite minimum time (IDMT) relay properties. Based on the severity the time is changed for the generation of trip signal. When the abnormal condition is occurred on the system, then trip signal is generated from the simulation circuit. This signal is available at the DAQ card digital output terminal, this signal is applied to the relay coil. The combination of relay coil and contactor is used for the isolation of faulted secession from the healthy circuit.

For the real time implementation the DAQ digital signal is connected to the relay signal terminal and relay get the supply from the DAQ $+\mathrm{Vcc}$ and ground terminals. The relay common terminal is connected to the single phase supply neutral terminal [26]. The supply phase terminal is connected to the contactor coil first terminal; the second terminal of the coil is connected to the normally close (NC) contact. When the abnormal condition occurred then relay energies the contactor coil, it isolate the faulted secession from the healthy secession.

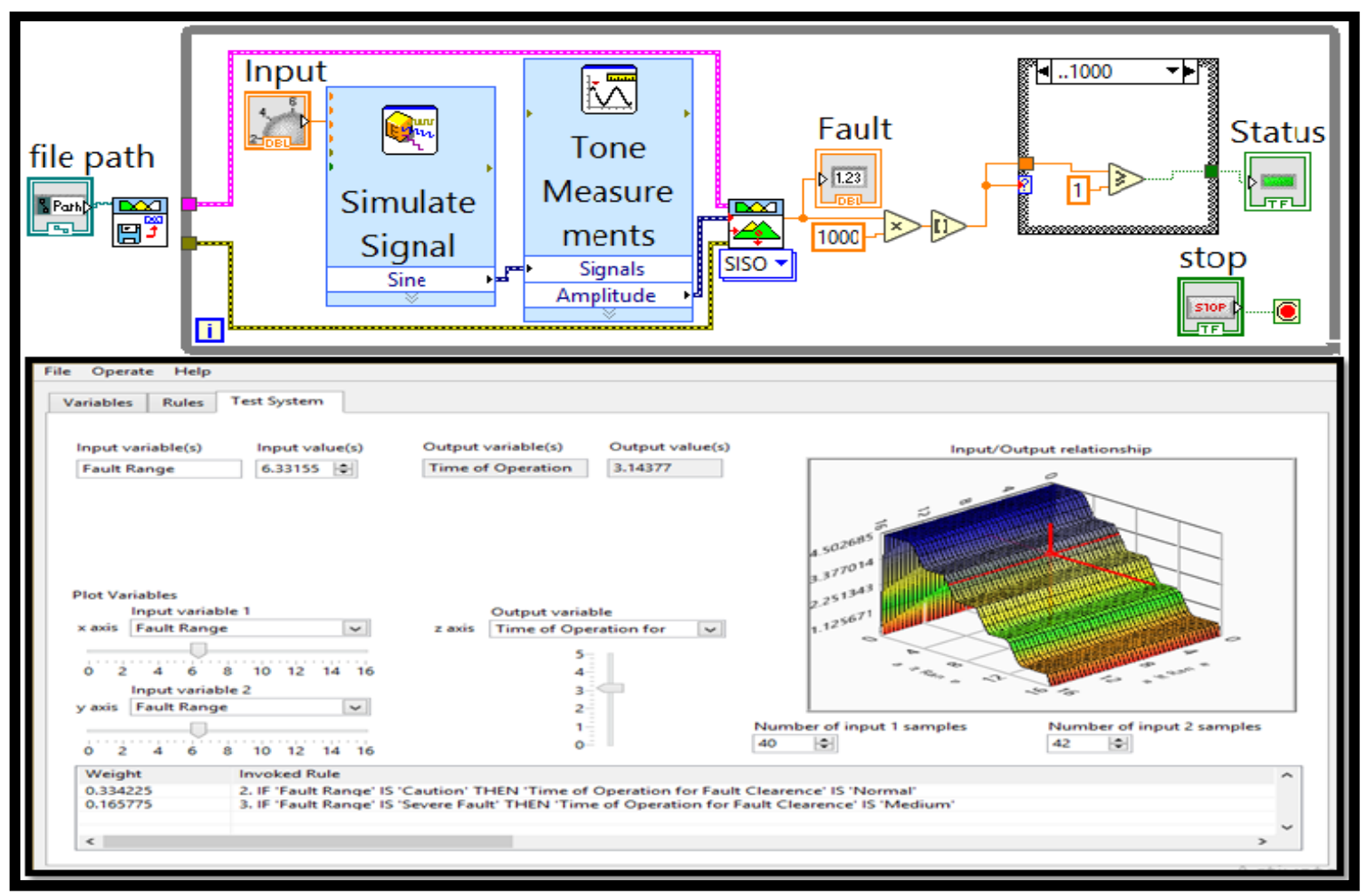

Figure 6. Simulation diagram for protection with fuzzy rules

For the different case studies, variation of voltage is created with auto transformer and motor generator set voltage (generator field) control method. Variation in frequency is created by controlling the speed of the motor-generator set through shunt motor armature and field control. For the over current protection, different types of loads are connected like pure resistive load (bulb), $\mathrm{R}-\mathrm{C}$ type (bulb-condenser) and R-L type (bulb-chokes) loads. With the motor-generator (MG) set frequency variations and voltage variation are created. The power is transmitted from the source to load through the transmission lines. With different types of loads at the receiving end different case studies are carried out.

\section{CONCLUSION}

In this paper phasor value of a voltage and current signals is calculated at the point of data acquisition. With computer based software program the measured values of current and voltage phasor values are very accurate. The protection scheme implemented by FBES system is generate the protection pulse in $1 \mathrm{~ms}$ for very severe fault. If the fault level is less than the time for generation of pulse protection is delayed. This FBES system also generates the protection pulse for the frequency variation, voltage variations and overload condition. The advantage of this FBES system is adaptable for the the accepted frequency values, 
voltage variations, and overload protection values range. The FBES protection scheme is tested for frequency variation of $+/-2 \%$ of nominal frequency, variation of voltage magnitude is $+/-10 \%$ of nominal voltage, over load protection for $>4 \mathrm{~A}$. This testing condition can apply to any system by changing the rating of voltage and current sensing devises with appropriate protection precautions.

\section{REFERENCES}

[1] D. M. Laverty, R. J. Best, P. Brogan, I. Al Khatib, L. Vanfretti and D. J. Morrow, “The OpenPMU Platform for Open-Source Phasor Measurements," IEEE Transactions on Instrumentation and Measurement, vol. 62, no. 4, pp. 701-709, 2013, doi: 10.1109/TIM.2013.2240920.

[2] IEEE Standard for Synchrophasor Measurements for Power Systems, IEEE Std. C37.118.1-2011.

[3] T. V. Muni and S. V. N. L. Lalitha, "Fast acting mppt controller for solar pv with energy management for dc microgrid," International Journal of Engineering and Advanced Technology, vol. 8, no. 5, pp. 1539-1544, 2019.

[4] C. R. Reddy and K. H. Reddy, "Passive islanding detection technique for integrated distributed generation at zero power balanced islanding," International Journal of Integrated Engineering, vol. 11, no. 6, pp. 126-137, 2019, doi: 10.30880/ijie.2019.11.06.014.

[5] K. P. P. Rao and P. S. Varma, "Analysis of very long distance AC power transmission line," International Conference on Electrical, Electronics, Communication, Computer, and Optimization Techniques (ICEECCOT), 2017, pp. 533-538, doi: 10.1109/ICEECCOT.2017.8284563.

[6] P. Zhang, H. Xue, R. Yang and J. Zhang, "Shifting Window Average Method for Phasor Measurement at Offnominal Frequencies," IEEE Transactions on Power Delivery, vol. 29, no. 3, pp. 1063-1073, 2014, doi: 10.1109/TPWRD.2014.2307059.

[7] S. Mondal, C. Murthy, D. S. Roy and D. K. Mohanta, "Simulation of Phasor Measurement Unit (PMU) using labview," 14th International Conference on Environment and Electrical Engineering, 2014, pp. 164-168, doi: 10.1109/EEEIC.2014.6835857.

[8] M. Wang and Y. Sun, "A practical, precise method for frequency tracking and phasor estimation," IEEE Transactions on Power Delivery, vol. 19, no. 4, pp. 1547-1552, 2004, doi: 10.1109/TPWRD.2003.822544.

[9] A. Cataliotti, V. Cosentino and S. Nuccio, "A Phase-Locked Loop for the Synchronization of Power Quality Instruments in the Presence of Stationary and Transient Disturbances," IEEE Transactions on Instrumentation and Measurement, vol. 56, no. 6, pp. 2232-2239, 2007, doi: 10.1109/TIM.2007.908350.

[10] M. K. Kumar, C. Veeranjaneyulu and S. P. Nikhil, "Interfacing of distributed generation for micro grid operation," Journal of Advanced Research in Dynamical and Control Systems, vol. 10, no. 4, pp. 472-477, 2018.

[11] G. Phadke and J. S. Thorp, "Synchronized Phasor Measurement and Their Applications," New York: Springer, Cham, 2008, doi: doi.org/10.1007/978-3-319-50584-8.

[12] K. Martin, "IEEE Standard for Synchrophasor Measurements for Power System IEEE Standard C37.118.1-2011," IEEE SA Standards Association, 2011.

[13] M. Donolo, "Advantages of synchrophasor measurements over SCADA measurements for the power system state Estimation," SEL Application Note (LAN 2006-10), 2006.

[14] M. V. Mynam, A. H. Kjrishna, and V. Singh, "Synchrophasors Redefining SCADA Systems," Journal International Association on Electricity Generation, Transmission and Distribution, vol. 26, no. 2, pp. 22-28, 2013.

[15] R. P. Haridas, "Synchrophasor Measurement Technology in Electrical Power system," International Journal of Engineering Research \& Technology, vol. 2, no. 6, pp.2063-2068, 2013.

[16] K. V. S. Reddy, B. Srinivasu, R. Pradeep, S. Shuvam and S. Vatsav, "Detection of islanding in micro grid using ROCOF," Journal of Advanced Research in Dynamical and Control Systems , vol. 10, no. 4, pp. 1029-1033, 2018.

[17] R. Thumu and K. H. Reddy, "A review on fuzzy-GA based controller for power flow control in grid connected PV System," International Journal of Electrical and Computer Engineering, vol. 7, no. 1, pp. 125-133, 2017, doi: 10.11591/ijece.v7i1.pp125133.

[18] P. K. Dash, K. R. Krishnanand, and M. Padhee, "Fast recursive Gauss-Newton adaptive filter for the estimation of power system frequencyand harmonics in a noisy environment," IET Gen.eration, Transmission \& Distribution, vol. 5, no. 12, pp. 1277-1289, 2011, doi: 10.1049/iet-gtd.2011.0034.

[19] J. Ren and M. Kezunovic, "Real-Time Power System Frequency and Phasors Estimation Using Recursive Wavelet Transform," IEEE Transactions on Power Delivery, vol. 26, no. 3, pp. 1392-1402, 2011, doi: 10.1109/TPWRD.2011.2135385.

[20] A. Monti, C. Muscas and F. Poni, "Phasor Measurement Units, and Wide Area Monitoring Systems," Academic Press, 2016.

[21] S. Chakrabarti and E. Kyriakides, "PMU Measurement Uncertainty Considerations in WLS State Estimation," IEEE Transactions on Power Systems, vol. 24, no. 2, pp. 1062-1071, 2009, doi: 10.1109/TPWRS.2009.2016295.

[22] K. Sarada and S. T. T. Ram, "Different ANN models for short term electricity price forecasting," International Journal of Recent Technology and Engineering, vol. 8, no. 3, pp. 6706-6712, 2019, doi: 10.35940/ijrte.C6895.098319.

[23] S. C. Sekhar, G. R. Kumar, and S. V. N. L. Lalitha, "Renewable energy integrated multi-terminal transmission system using wavelet based protection scheme," International Journal of Power Electronics and Drive Systems, vol. 10, no. 2, pp. .995-1002, 2019, doi: 10.11591/ijpeds.v10.i2.pp995-1002.

[24] Ch. R. Reddy and K. H. Reddy, "Islanding detection techniques for grid integrated distributed generation -A review," International Journal of Renewable Energy Research, vol. 9, no. 2, pp. 960-977, 2019, doi: 10.20508/ijrer.v9i2.9371.g7661.

[25] S. Munnangi, M. S. Krishna and Y. S. Rao, "Multi terminal transmission line fault detection using ANN and wavelet packet decomposition," International Journal of Engineering and Advanced Technology, vol. 8, no. 4, pp. 1232-1237, 2019.

[26] C. Sriram and Y. Kusumalatha, "A review on power swing blocking schemes of distance relay during stable power swings," International Journal of Engineering and Advanced Technology, vol. 8, no. 4, pp. 636-641, 2019. 


\section{BIOGRAPHIES OF AUTHORS}
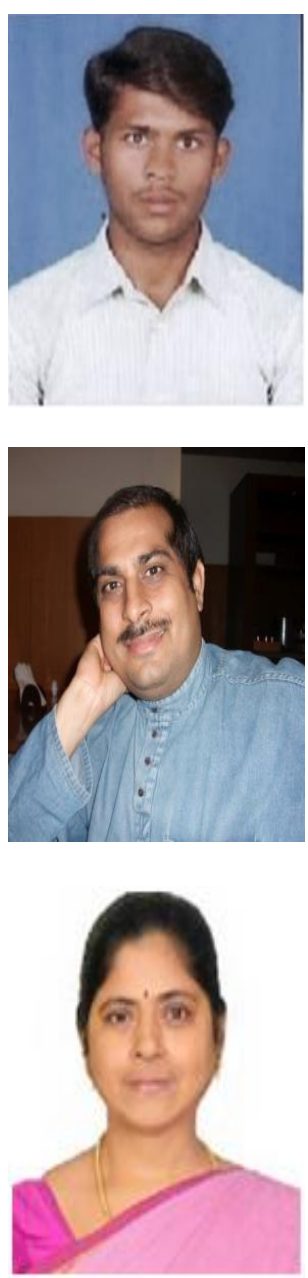

Ravi Ponnala (D) SI SC P Received the Bachelor of Technology degree in Electrical \& Electronics Engineering from Vidya Bharathi Inistitute of Technology (Jawaharlal Nehru Technological University Hyderabad) in 2010 and Master of Technology degree in Power Electronics \& Electric Drives from Vardhaman College of Engineering (Jawaharlal Nehru Technological University Hyderabad), India in 2013. He is currently research scholar (P) in Koneru Lakshmaiah Education Foundation (K.L.E.F.) deemed to be University, Guntur, India. Assistant Professor in Vasavi College of Engineering (A), Hyderabad. Area of interest is wide area power system monitoring and protection in dynamic state using synchronized phasor measurements with less data storage system, live phasor representation of real power system, development of smart grid model test bed system. He can be contacted at email: ravi.ponnala@staff.vce.ac.in.

Muktevi Chakravarthy (iD) SC P is working as a Professor and Head of the Department of EEE, Vasavi College of Engineering, Hyderabad, India. In He obtained his Ph.D degree from Jawaharlal Nehru Technological University Hyderabad, India in 2013. Obtained his M.Tech degree in power systems from Jawaharlal Nehru Technological University Kakinada, India in 2005. Obtained his B.Tech degree from Nagarjuna University Guntur, India in 1999. He has 18 years of experience in Teaching \& Research and He provided consultancy to M/s NR Bearings Pvt. Ltd. on Automation of Cage Brightening Station. His areas of research include power system monitoring and protection, smart grids, hybrid vehicles, solar power MPPT and development of hardware and software for microprocessor/microcontroller applications. He can be contacted at email: hodeee@staff.vce.ac.

Suraparaju Venkata Naga Lakshmi Lalitha (D) SII SC P is working as a Professor in the Department of Electrical and Electronics Engineering, Koneru Lakshmaiah Education Foundation (K.L.E.F.) deemded to be University, Vijayawada, India. She obtained her Master of Technology and Ph.D degree from National Institute of Technology, Warangal, Telangana, India. She obtained her B. Tech degree from Sri Venkateshwara University, Tirupathi, and Andhra Pradesh, India. Her areas of research include power system restructuring, distribution systems, smart grids, meta heuristic techniques application to power system, Wide area power system monitoring and protection in dynamic state using synchronized phasor measurements, static and dynamic state estimation incorporating synchro phasor measurements, transient fault detection and analysis of microgrid connected power system. She can be contacted at email: lalitha@kluniversity.in. 